\title{
Assessing capability in economic evaluation: a life course approach?
}

\author{
Joanna Coast ${ }^{1}$ \\ Published online: 8 January 2019 \\ (c) Springer-Verlag GmbH Germany, part of Springer Nature 2019
}

\section{Introduction}

One man in his time plays many parts... at first, the infant... then the whining schoolboy... then the lover... then a soldier... then the justice... The sixth age shifts... with spectacles on nose... and his big manly voice turning again toward childish treble... last scene of all... is second childishness and mere oblivion... (William Shakespeare's the Seven Ages of Man, from As You Like It).

Despite having been written around 400 years ago, William Shakespeare's view of the roles that people play during their lives still resonates. As they move through their lives and 'play' these different 'parts', it might be expected that different things are important to people, and that this might, therefore, affect their values. In contrast, most measurement within health and social care, particularly among health economists, tends to start from the assumption that the outcome of interventions, treatments and service can be measured across these different stages of life with no, or almost no, change in what is being measured and how it is being valued. Instead, quality of life is generally measured using so-called generic health status measures (i.e. measures that can, in theory, be applied across all interventions and to all population groups) [1].

There are huge advantages for decision-making in using a generic measure: such a measure maintains the consistency across evaluations, and thus provides the comparability that enables decisions to be made about the relative allocation of resources to different treatments, interventions, services and programmes within health care. There are, however, also disadvantages with the use of generic measures, with

Joanna Coast

jo.coast@bristol.ac.uk

1 Health Economics at Bristol, Health and Population Sciences, Bristol Medical School, University of Bristol, 1-5 Whiteladies Road, BS8 1NU Bristol, UK perhaps the most commonly considered relating to the sensitivity of the measures to different interventions for different conditions. A less discussed issue is around whether different parts of the life course need different measures for an evaluation to properly capture benefit. In part, this may depend upon the complexity of the measure. One very simple measure of outcome that is relevant to both health and capability is mortality. Whilst the importance, meaning and implications of mortality might be different for these different stages of life, as an objective measure, being alive or dead does, unambiguously, represent the same actual outcome at all these stages. It could thus provide a measure that is applicable across the life course, even if its value differs at different stages of life.

Once we move to more complex measures of health or capability wellbeing, however, both what it is important to measure and how it is valued may differ according to life stage. In general, this problem is not well acknowledged in economic decision making in health, with its attempt to compress all decisions into the same outcomes framework, where the health benefits to infants, adults and the older person at the end of life are all measured, at least theoretically, in the same manner. Some small concessions to difference are made in the case of children, but the approach within the mainstream has been to continue to utilise essentially the same measure (as, for instance, with the EuroQol Group's EQ-5D-Y which slightly rewords the EQ-5D for children so that: (i) the language is more simple, for example, "worried, sad or unhappy" replacing "anxious or depressed"; and (ii) relevant examples are introduced, for example, "going to school" and "playing" rather than "work, study, housework" within the "usual activities' dimension [2]). There are problems with this solution, however, in that many studies choose not to use these measures for children because of their perceived lack of appropriateness $[3,4]$. New health measures for use with children are being developed [5-11], but it is not entirely clear how these should be used in economic evaluations that move across the life course; specifically, it is unclear where the shift in measures should occur, and how different measures should be related to one another within a decision making framework. 
So, although economic evaluation is inevitably reductionist because of the desire for comparability, it may be that this reductionism has gone too far in the case of the outcome measures used for economic decision making. A capability framework might provide one means of conceding more divergence in what is measured and valued for those at different stages along the life course. Indeed, the capability approach is open about the need for the possibility of the important domains of wellbeing being related to the particular context under consideration [12-15], and exploration of the life course might be one way of accounting for this whilst obtaining greater sensitivity in measurement but also retaining the generic nature of measures within stages of the life course.

The capability approach has been developed through the work of Amartya Sen and others, including Sabine Alkire, Martha Nussbaum, and Ingrid Robeyns, over the last forty years [12-24]. It is essentially "a broad normative framework for the evaluation and assessment of individual wellbeing and social arrangements, the design of policies, and proposals about societal change" (Robyens [15], p. 352) that concentrates on changing the evaluative space from one that is focused on either resources (wealth or income) or utility (essentially happiness) to one that is focused on capability. Capability is concerned with "functionings and capabilities to function" (Sen [12], p. 32) where functionings for any individual are "the various things that he or she manages to do or be in leading a life" (Sen [12], p. 31). Capabilities are thus concerned with the freedom to live a life that is of value.

Over recent years the capability approach has made inroads into many different sectors including health [25], with general interest in the approach from the perspectives of justice in health and health care [26-30] and from a focus on patient experience [31-33]. Capability approaches to economic decision making in health and social care have been increasingly advocated over recent years [34-38] and there is a rising number of capability-based instruments that have been developed for use in economic evaluation [39]. These include both measures intended to estimate impacts on capability in specific contexts-including mental health conditions [40], chronic pain [41], public health [42] and women's health [43] - and generic measures intended for the whole population. These latter measures include the ICECAP measures, which focus on whole populations at different stages of the life course [44-49].

\section{Conceptualising capability in relation to the life course: the ICECAP measures}

There is evidence that health state [50] and happiness [51] vary across different stages of life, but this is not the same as asking whether the components of wellbeing (from a capability perspective, what is valued and what there is reason to value) differ as people move through different stages of life. This question of what is valued, and what there is reason to value, is likely to depend on age, but also on the context in which that age is experienced. The notion of the 'life course' brings together these two ideas [52]. The life course concept generally focuses on the interlinking between generation and age, such that influences on development are related both to the context and circumstances in which a person is born (their birth cohort) and the age of that person. Development is thus related to historical context, current social norms, links between generations and previous choices made by the person, as well as the age of that person [52]. Many of these factors also seem to apply to the development of personal values. A summary of the evidence by Hitlin and Paliavin, suggests that values are affected by many contextual factors including historical context and parental influences [53]. They also note, however, that " $a$ temporal dimension about values is virtually absent from the literature" (Hitlin \& Paliavin [53], p. 384), suggesting that an important area for research is to determine what values individuals hold at particular points across the life course.

The ICECAP measures provide a 'family' of measures to use in assessing capability wellbeing for economic evaluation and so may assist in exploring differences in values across the life course. To date there are three ICECAP measures: the ICECAP-O (Older people) is a measure of the capability for a good life for older people [45, 46]; the ICECAPA (Adult) is a measure of the capability for a good life for the whole adult population [48, 49]; and the ICECAP-SCM (Supportive Care Measure) [44, 47] is intended to measure the opportunity for a good death $[54,55]$. Each of the measures has been developed in largely the same way (albeit with some small differences) beginning with a first stage of in-depth interviews to generate conceptual attributes for the measure and followed by a second stage of repeat interviews to check the conceptual attributes and generate meaningful wording for each of these attributes. The third stage has generated values for each measure, using best-worst scaling $[56,57]$, and the fourth has involved the assessment of the measure in practice, considering issues such as feasibility of use, validity, reliability and sensitivity to change.

The application of the capability approach within the ICECAP programme has started anew with the generation of measures for each stage of life so far considered. As the development of attributes within the ICECAP measures rests on discussion with informants in the relevant groups about what is important to them in their lives, these attributes can be used to consider the question of changing values across different stages of life, and they do provide evidence of such changes, with differences found between the different groups interviewed for the various ICECAP studies. Whilst ICECAP-O and ICECAP-A are broadly similar in terms of 
the values that seemed to be important to people there are some important differences that may reflect these life course issues. ${ }^{1}$ Three of the attributes are almost identical. These are Attachment, Enjoyment and Autonomy/Control which appear in both measures with only minimal differences in wording. There are greater differences with the two other attributes, however.

The first of these is Achievement in ICECAP-A which has some similarities to the notion of Role in ICECAP-O but is not identical to it. In the development paper, Achievement (ICECAP-A) is seen as going beyond Role (ICECAP-O) to "encompass progressing and excelling in life" (Al-Janabi [48], p. 173) which may not be achieved purely by the presence of a role in life. In the development work for ICECAP$\mathrm{A}$, the capability of Achievement was "strongly related to their opportunities to be successful at work, to have a family and to own things" (Al-Janabi [48], p. 171) For an older population group, however, this ability to achieve, which might be important in earlier life, may have dissipated in importance. This view is supported by work using thinkaloud techniques with ICECAP-A to determine individuals' thought processes as they complete the measure, which suggested that some older people struggle with the concept of Achievement, finding it difficult to relate the terminology within the measure to a stage of life where they are no longer seeking to progress [58].

The second attribute where there are differences is Stability in ICECAP-A, which is similar to the attribute of Security in ICECAP-O. The distinction between the two attributes was explained in the orgininal ICECAP-A paper as being between the emphasis on Stability "in the present (in terms of current feelings of comfort and continuity) as well as the future" (Al-Janabi [48], p. 173), and the focus of Security on anxieties about the future and what might happen [45]. This focus on Security appeared to reflect the greater uncertainty in the lives of older people about both their wealth and, particularly, their health.

Overall, then, there do appear to be some distinctions across adult life, as reflected within the ICECAP measures. These distinctions become very much larger, however, once the focus shifts from these stages of life that are primarily concerned with a good life, towards those that concentrate on the opportunity for a good death. The ICECAP-SCM has much greater variation within its attributes, with these relating to general wellbeing (Choice, Love and affection, Preparation) as in the other two ICECAP measures, but also more directly to health (freedom from Physical suffering and

\footnotetext{
${ }^{1}$ In-depth interviews for ICECAP-O included those aged 65 and over, whilst those for ICECAP-A included informants aged 18 and over; of the ICECAP-A informants, 9 of the 36 were aged 65 and over.
}

freedom from Emotional suffering) and to care (Support and Dignity). Of course, unlike the other 'ages of man' which are sequential, end of life could come at any point in life and not just in Shakespeare's "last scene of all... second childishness and mere oblivion, sans teeth, sans eyes, sans taste, sans everything". It thus differs more clearly both in nature and focus (a good death, rather than a good life) from the other stages. Evidence from thinkaloud research also indicates that those individuals at the very end of life tended to find the ICECAP-SCM more appropriate to their situation than the ICECAP-A, whilst those earlier in the trajectory towards death thought that ICECAP-A was more relevant [59], again implying a shift in values across the life course.

It seems, from the work on ICECAP so far, that it may be appropriate for capability measures to follow a life course approach in which values are elicited that are specific to the particular stage of life that a person is at, but in which these values are integrated into an overall framework to preserve the ability to make decisions across different stages of the life course. It is also important to note that, in keeping with life course approaches, the values expressed in the ICECAP measures are directly related to the context (of an industrialised society in the early twenty-first century) in which they were generated. Life course approaches would suggest that the values obtained for the ICECAP measures are likely to be related to the context in which people live, the rapidly changing social norms that have been experienced over the period of their lives, the values that come from the influence of their family and the generations before, and the choices that have led them to their current situation, as well as the indidual's stage of life. It should be noted, therefore, that the attributes within the measures are not just related to stage of life, but are inextricably bound with their historical and social context. Indeed, the first ICECAP paper, which resulted in the generation of the attributes for ICECAP-O noted this importance of context, commenting that "on no occasion was the basic capability of nourishment that is the focus of many of Sen's examples discussed by informants" (Grewal [45], p. 1899). This is almost certainly related to the context of the particular UK society at the time that interviews were undertaken, and contrasts with other work in LMICs [43]. In taking forward a life course approach to measurement and valuation, it will be important to focus not just on stage of life, but also these other aspects of context, particularly when considering the generalisability of findings. Nevertheless, even focusing on stage of life, requires a significant degree of further research. 


\section{An agenda for research: populating a capability framework across the life couse}

As yet, there is no ICECAP measure developed for use with children, and a paucity of work on values across the life course. To fully elaborate a capability framework across the life course, therefore, seems to require two major research endeavours. The first is to generate appropriate measures for children; the second is to develop a framework in which these different elements come together.

There are a number of issues in extending the ICECAP framework to children. First, there is the question of how many stages of life childhood encompasses. Shakespeare clearly sees at least two ('infant' and 'schoolboy'), but 'the lover' could perhaps be seen as the stage of adolescence, a time which has also been referred to as 'emerging adulthood' [60], and more stages may be required to fully encompass issues of child development. Values may differ across these different stages of childhood and so it is important to understand and account for these different stages. A second issue that is specific to children, is the need to focus on both well-being and well-becoming, where the former is concerned with current well-being and the latter is concerned more with the opportunities for development that a child has. The focus on measuring benefits to children outside of health economics has, until recently, focused on well-becoming and is now changing to encompass both perspectives [61]. In contrast, in health economics insofar as health benefits to children have been distinguished from those for adults, they have largely focused on well-being rather than well-becoming [2, 62]. In taking forwards a capability approach that covers the childhood element of the life course, it seems important to focus on "opportunities for present and future functioning" (Biggeri and Santi [63], p. 375)—on both well-being and well-becoming - as both are likely to form important components of value during these stages of life that are so important for development. Linked with this issue of wellbeing and well-becoming, are questions of the logistics of gaining information from children and young people, particularly those of very young age, and the question of whose views are most appropriate to use in decision making across the different stages of childhood.

Generating a framework of measures that operate throughout the life course requires a means of integrating these different measures such that decisions can be made across the life course, not for just one element of it. To ensure that this is possible, it is key that the different measures are similar in their construction: that they are developed using similar methods, valued using similar methods and anchored at the same points. To date, this is the case for the ICECAP measures, which have all been generated from in-depth interviews with the relevant population, valued using best-worst scaling, and anchored at zero (for no capability) and one (for full capability). As long as these theoretical anchors are meaningful, then it should be possible to shift between measures, although some evidence that this is the case, would be important to obtain. If it is assumed that it is feasible to shift between measures, then there are important questions about the nature of that shift, including whether it should be related to chronological age (apart from the move into end of life which is determined more by likely prognosis) or by some other factor such as cognitive ability, and whether the shift should be immediate on reaching a particular point (e.g. age) or involve a more gradual transfer between instruments. As yet, there has been little thought given to these issues in the published literature and it is clear that both normative and methodological research would be needed, with exploratory research required with both respondents to the measures and policy makers. It should be noted that these issues are of wider concern: moving from a preference-based child health measure to a preference-based adult health measure to generate QALYs across the life course raises similar challenges.

To conclude, utilising capability measures within a life course approach is not something that has been previously considered, yet it sits well with the general principles of Sen's view of the capability approach, in which context is important in determining the objects of value. Although this inevitably requires a more complex approach to economic decision making, the benefits of capturing what is actually important to people at different stages of their lives, may make the additional complexity worthwhile. Life course approaches to capability measurement may, therefore, offer a promising research avenue for innovative means of improving decision making in health and social care.

Acknowledgements I would like to thank the following for comments on earlier drafts of this paper: Hareth Al-Janabi; participants at a seminar at Hitotsubashi University, Japan in February 2015; participants at the Health Economists' Study Group meeting in June 2015; participants at the Human Development and Capability Association conference in September 2016; participants of the Vancouver Health Economics meeting in May 2018.

Funding This research was funded by the European Research Council (261098 EconEndLife); Wellcome (205384/Z/16/Z).

\section{Compliance with ethical standards}

Conflict of interest The author is one of the developers of the ICECAP suite of capability wellbeing measures. 


\section{References}

1. Pietersma, S., van den Akker-van, M.E., Marle, de Vries, M.: Generic quality of life utility measures in health-care research: conceptual issues highlighted for the most commonly use utility measures. Int. J. Wellbeing 3(2), 173-181 (2013)

2. Wille, N., et al.: Development of the EQ-5D-Y: a child-friendly version of the EQ-5D. Qual. Life Res. 19, 875-886 (2010)

3. Griebsch, I., Coast, J., Brown, J.: Quality-adjusted life-years lack quality in pediatric care: a critical review of published cost-utility studies in child health. Pediatrics 115, 600-614 (2005)

4. Ungar, W.J.: Challenges in health state valuation in paediatric economic evaluation: are QALYs contraindicated? Pharmacoeconomics 29(8), 641-652 (2011)

5. anon: Changing needs and changes needed. Health Serv. J. 4, 17 (1991)

6. Ratcliffe, J., et al.: Valuing child health utility 9D health states with a young adolescent sample: a feasibility study to compare best-worst discrete choice experiment, standard gamble and time trade off methods. Appl. Health Econ. Health Policy 9, 15-27 (2011)

7. Ratcliffe, J., et al.: Developing adolescent-specific health state values for economic evaluation. Pharmacoeconomics 30, 713-727 (2012)

8. Ratcliffe, J., et al.: Valuing the Child Health Utility 9D: using profile case best worst scaling methods to develop a new adolescent specific scoring algorithm. Soc. Sci. Med. 157, 48-59 (2016)

9. Stevens, K.: Working with children to develop dimensions for a preference-based, generic, pediatric health-related quality-of-life measure. Qual. Health Res. 20, 240-351 (2010)

10. Stevens, K., Palfreyman, S.: The use of qualitative methods in developing the descriptive systems of preference-based measures of health-related quality of life for use in economic evaluation. Value Health 15(8), 991-998 (2012)

11. Stevens, K.J.: Assessing the performance of a new generic measure of health related quality of life for children and refining it for use in health state valuation. Appl. Health Econ. Health Policy 9(3), 157-169 (2011)

12. Sen, A.: Capability and Well-Being. In: Nussbaum, M.C. (ed) The Quality of Life. Clarendon Press, Oxford (1993)

13. Alkire, S.: Why the capability approach? J. Hum. Dev. 6, 115-133 (2005)

14. Alkire, S.: Using the capability approach: prospective and evaluative analyses. In: Comin, F., Qizilbash, M., Alkire, S. (eds.) The Capability Approach: Concepts, Measures and Applications. Cambridge University Press, New York (2008)

15. Robeyns, I.: The capability approach in practice. J. Political Philos. 14, 351-376 (2006)

16. Sen, A.: Inequality Reexamined. Russell Sage Foundation, New York (1992)

17. Sen, A.: Choice, Welfare and Measurement. Harvard University Press, Cambridge (1982)

18. Sen, A.: Human rights and capabilities. J. Hum. Dev. 6, 151-166 (2005)

19. Sen, A.: The Idea of Justice. Allen Lane, London (2009)

20. Nussbaum, M.C.: Capabilities as fundamental entitlements: sen and social justice. Fem. Econ. 9(2-3), 33-59 (2003)

21. Nussbaum, M.C.: Creating capabilities: the human development approach. Harvard University Press, Cambridge (2011)

22. Alkire, S., Deneulin, S., The Human Development and Capability Approach. In: Deneulin, S., Shahani, L. (eds) An Introduction to the Human Development and Capability Approach. Freedom and Agency, p. 22-48. Earthscan, London (2009)

23. Robeyns, I.: Sen's capability approach and gender inequality: selecting relevant capabilities. Fem. Econ. 9(2-3), 61-92 (2003)
24. Robeyns, I.: The capability approach: a theoretical survey. J. Hum. Dev. 6, 93-114 (2005)

25. Mitchell, P., et al., Applications of the capability approach in health: a literature review. Soc. Indic. Res. 133(1), 345-371 (2016)

26. Venkatapurum, S.: Health justice: an argument from the capabilities approach. Polity Press, Cambridge (2011)

27. Ruger, J.P.: Millenium development goals for health: building human capabilities. Bull. World Health Organ. 82, 951-952 (2004)

28. Ruger, J.P.: Ethics and goverance of global health inequalities. J. Epid. Comm. Health 60, 998-1003 (2006)

29. Ruger, J.P.: Health capability: conceptualization and operationalization. Am. J. Public Health 100, 41-49 (2010)

30. Ruger, J.P.: Health, capability and justice: toward a new paradim of health ethics, policy and law. Cornell J. Law Pub. Policy 403, 403-482 (2006)

31. Entwistle, V., et al.: Which experiences of health care delivery matter to service users and why? A critical interpretive synthesis and conceptual map. J. Health Serv. Res. Policy 17(2), 70-78 (2012)

32. Entwistle, V.A., Watt, I.S.: Treating patients as persons: a capabilities approach to support delivery of person-centred care. Am. J. Bioeth. 13(8), 29-39 (2013)

33. Ryan, M., et al.: Valuing patients' experiences of healthcare processes: towards broader application of existing methods. Soc. Sci. Med. 106, 194-203 (2014)

34. Coast, J., Smith, R.D., Lorgelly, P.: Should the capability approach be applied in health economics? Health Econ. 17, 667-670 (2008)

35. Coast, J., Smith, R.D., Lorgelly, P.: Welfarism, extra-welfarism and capability: the spread of ideas in health economics. Soc. Sci. Med. 67, 1190-1198 (2008)

36. Anand, P., Dolan, P.: Equity, capabilities and health. Soc. Sci. Med. 60, 219-222 (2005)

37. Smith, R.D., et al., The Capability Approach: An Alternative Paradigm for Health Economics? In: Jones, A. (ed) Elgar Companion to Health Economics. Edward Elgar Publishing, Cheltenham (2012)

38. Lorgelly, P.K., et al.: Outcome measurement in economic evaluation of public health interventions: a role for the capability approach? Int. J. Environ. Res. Pub. Health 7, 2274-2289 (2010)

39. Coast, J., Kinghorn, P., Mitchell, P.: The development of capability measures in health economics: opportunities, challenges and progress. Patient 8, 119-126 (2015)

40. Simon, J., et al.: Operationalising the capability approach for outcome measurement in mental health research. Soc. Sci. Med. 98, 187-196 (2013)

41. Kinghorn, P., Robinson, A., Smith, R.D.: Developing a capability-based questionnaire for assessing well-being in patients with chronic pain. Soc. Indic. Res. 120, 897-916 (2014)

42. Lorgelly, P.K., et al.: Operationalising the capability approach as an outcome measure in public health: the development of the OCAP-18. Soc. Sci. Med. 142, 68-81 (2015)

43. Greco, G., et al.: What is a good life? Selecting capabilities to assess women's quality of life in rural Malawi. Soc. Sci. Med. 130, 69-78 (2015)

44. Huynh, E., et al.: Values for the ICECAP-Supportive Care Measure (ICECAP-SCM) for use in economic evaluation at end of life. Soc. Sci. Med. 189, 114-128 (2017)

45. Grewal, I., et al.: Developing attributes for a generic quality of life measure for older people: preferences or capabilities? Soc. Sci. Med. 62, 1891-1901 (2006)

46. Coast, J., et al.: Valuing the ICECAP capability index for older people. Soc. Sci. Med. 67, 874-882 (2008) 
47. Sutton, E., Coast, J.: Development of a supportive care measure for economic evaluation of end-of-life care, using qualitative methods. Palliat. Med. 28, 151-157 (2014)

48. Al-Janabi, H., Flynn, T.N., Coast, J.: Development of a self-report measure of capability wellbeing for adults: the ICECAP-A. Qual. Life Res. 21, 167-176 (2012)

49. Flynn, T.N., et al.: Scoring the ICECAP-A capability instrument. Estimation of a UK general population tariff. Health Econ. 24(3), 258-269 (2015)

50. Sorensen, J., et al.: Danish EQ-5D population norms. Scand. J. Pub. Health 37, 467-474 (2009)

51. Blanchflower, D.G., Oswald, A.J.: Well-being over time in Britain and the USA. J. Pub. Econ. 88, 1359-1386 (2004)

52. Elder, G.H.: Human agency, and social change: perspectives on the life course. Soc. Psychol. Q. 57(1), 4-15 (1994)

53. Hitlin, S., Piliavin, J.A.: Values: reviving a dormant concept. Ann. Rev. Sociol. 30, 359-393 (2004)

54. Coast, J.: Strategies for the economic evaluation of end-of-life care: making a case for the capability approach. Expert Rev. Pharmacoecon. Outcomes Res. 14(4), 473-482 (2014)

55. Coast, J., et al., Measuring and Valuing Outcomes for Care at the End of Life: the Capability Approach. In: Round, J., (ed) Care at the End of Life. An Economic Perspective, p. 89-102. Springer, Basel (2016)

56. Flynn, T.N., et al.: Best-worst scaling. What it can do for health care research and how to do it. J. Health Econ. 26, 171-189 (2007)
57. Louviere, J.J., Flynn, T.N., Marley, A.A.J.: Best-worst Scaling: Theory, Methods and Applications. Cambridge University Press, Cambridge (2015)

58. Al-Janabi, H., et al.: Can capabilities be self-reported? A think aloud study. Soc. Sci. Med. 87, 116-122 (2013)

59. Bailey, C., et al., The ICECAP-SCM tells you more about what I'm going through: a think-aloud study measuring quality of life among patients receiving supportive and palliative care. Palliat. Med. 30(7):642-652 (2016)

60. Bynner, J.: Rethinking the youth phase of the life-course: the case for emerging adulthood? J. Youth Stud. 8(4), 367-384 (2005)

61. Ben-Arieh, A.: The child indicators movement: past, present, and future. Child Indic. Res. 1, 3-16` (2008)

62. Stevens, K.: Developing a descriptive system for a new preferencebased measure of health-related quality of life for children. Qual. Life Res. 18, 1105-1113 (2009)

63. Biggeri, M., Santi, M.: The missing dimensions of children's well-being and well-becoming in education systems: capabilities and philosophy for children. J. Hum. Dev. Capab. 13(3), 373-395 (2012)

Publisher's Note Springer Nature remains neutral with regard to jurisdictional claims in published maps and institutional affiliations. 